\title{
ASSESSMENT OF THE CHILDREN MANUAL DEXTERITY AND HAND GRIP STRENGTH: TEST-RETEST RELIABILITY STUDY
}

\author{
M. KAMIENIARZ ${ }^{1}$, W. STRYLA ${ }^{1}$, P. KOWALSKA ${ }^{2}$, G. KAMIENIARZ ${ }^{2}$ \\ ${ }^{1}$ Clinic of Rehabilitation, K. Marcinkowski University of Medical Sciences, Poznań, Poland \\ ${ }^{2}$ Computational Physics Division, Department of Physics, A. Mickiewicz University, Poznań, Poland
}

(Received 6 July 2001)

\begin{abstract}
A study was undertaken to verify reliability of both the new computer tests of manual dexterity and known dynamometric and Nine-Hole Peg tests in two groups of 84 (average age $10.5 \pm 2.4$ ) and 61 (average age $11.02 \pm 2.45$ ) children aged from 7 to 15 , respectively. In these groups the series of measurements was twice repeated. A detailed statistical analysis of the results was made and indices describing reliability of the tests were determined. Correlation coefficients between the tests performance in the first and second series of measurements (at a week distance) by children from the same group were calculated proving a high and statistically significant correlation between the measurements. A comparison of the Pearson's coefficients calculated from our data with corresponding values for the tests known from literature proved a very good agreement. In addition, to check the computer tests stability, the statistical significance of differences between the average values of times of the tests completion in the two series, was analysed.
\end{abstract}

Keywords: manual dexterity, children, test reliability

\section{INTRODUCTION}

Manual performance of man is closely related to the multidirectional control of the central nervous system, which is manifested e.g. by a much greater volume of the cortex engaged in controlling the actions of the upper than the lower limb.

The hand is a receptor of much information from the environment and in everyday life all kinds of grips are of vital importance for ordinary activities in daily life. The loss of hand or its dysfunction is a great handicap. The rehabilitation of patients with upper limb dysfunction should be directed to maximum possible restoration of manual functioning.

The assessment of progress in rehabilitation should be performed in a possibly objective way. Since the literature on objective assessment of manual dexterity by computer tests is scarce, we have prepared some tests described in detail in our previous paper [6] and we established standard times of their performance in a representative group of healthy children. These results can be a reference for those obtained for patients with all kinds of hand dysfunction. However, before checking this possibility of application of our tests we have to verify if they are adequate and can be used in clinical practice. Preliminary results reported in [6] (Kamieniarz et al., 2001) based on a study of three functional tests performed in a group of 34 children indicated reproducibility of results. Nevertheless a systematic study of all the tests in a larger group of children seemed needed to verify the reliability of the tests proposed in [6]. 


\section{THE AIM OF THE STUDY}

The aim of the study was twofold: a) to check the reliability of the tests of manual dexterity proposed in [6] by performing two series of measurements of the time of the tests completion in the group of 84 school age children; b) to perform the test-retest reliability study for known handgrip strength and Nine-Hole Peg tests in the separate control group.

\section{THE METHOD AND SUBJECTS}

The tests proposed aimed at performance of six tasks displayed on a computer screen using a computer mouse. The supervising person measures the time of the task completion and other parameters checking the accuracy of the task performance [6]. The tasks are easy to perform, diverse, colourful and are proposed as a kind of play, so are made to be attractive for children.

The first study was performed in a group of 84 elementary school pupils at one of primary schools in Poznań. Each level of teaching was represented by 12 randomly chosen volunteers. The children were from 7 to 15 years of age, the average age was $10.5 \pm 2.4$. The children were of different age, sex, either familiar with a computer or not able to use it. Although initially we assumed that each child performs 3 tasks assigned randomly, it proved impossible to maintain the same total number of children carrying out particular tests so that we encountered fluctuations of that number from 34 do 39 .

About 1 year later, when the first experiment and its analysis was completed, the second study was carried out in other two schools among 61 children (average age $11.02 \pm 2.25$ ). We aimed at comparing the values of the Pearson's correlation coefficients for the computer tests with those for the dynamometric and functional tests. The Pearson's correlation coefficients have not been reported in literature, as for as we know, for children aged 7-15. Mainly for the logistic reasons, it was easier to perform the second study using a different sample. In order to cany out the second study we needed special equipment (the JAMAR hand dynamometer and the standardised NineHole Peg Board) which was not available to us during our reliability study of the computer tests.

Prior to the studies each child was instructed on the principles of carrying out the tests, and when necessary the child was explained how to use a computer mouse and to operate the hand JAMAR dynamometer and the Nine-Hole Peg Test. Before taking up the proper test the child could cany out a few trials. Then, the child participating in the first study was asked to perform three computer tests and the results were fed to a computer. Each task was three times repeated for the right and the left hand separately. Since the children may have got tired with so many tests, we have reduced their number to three randomly selected out of the possible six to be performed by each child. After one week the same children performed the same tests in the same conditions once again in both groups.

In a test checking a particular functional behaviour care must be taken to ensure that the measuring instrument measures the exact feature desired. It should be measured in a reliable way. Nevertheless, each measurement can be charged with an error [2, 8]. The source of error could be the random variation of a functional feature of the subjects performing a given test (e.g. deconcentration because of being tired, psychological state, changes in the environment) 
or/and the impediment of the test whose results may be influenced by repetition. In the latter case the apparent change in a given feature reflects the process of learning although the feature remains unchanged. Therefore, a good test should give stable results for the same person in repeated measurements or in other words the result should be the same when the measurement is repeated in the same conditions. It is assumed that the test is reliable [13] when the results obtained for the same person measured by different supervising persons are close.

One of the methods of checking the test-retest reliability is the reproducibility of its results. The degree of agreement between results of measurements made at different times and in the same conditions can be calculated by analysis of correlation [8] and the Pearson's coefficient is a measure of reliability.

\section{STATISTICAL ANALYSIS OF RESULTS}

The three times of performance of each task measured for each child were averaged. As far as the computer tests are concerned, in paper [6] we have proved that to obtain a gaussian distribution of results for each age group the data should be transformed by taking logarithms of mean times of the task performance, therefore, this procedure was accepted in this work. Statistical analysis was made of the results obtained for the whole group of children performing a given task, without division into subgroups according to sex or familiarity with a computer. Statistical analysis was made using the program Instat.

\section{REGRESSION AND CORRELATION ANALYSIS RESULTS}

Tables 1 and 2 present results of detailed analyses of correlation and regression for all tasks. Table 1 refers to the results obtained for the dominant hand. The subsequent columns give: particular task, total number of children performing the task, Pearson's $\left(r_{p}\right)$ coefficients of linealcorrelations, Spearman's $\left(r_{s}\right)$ correlation coefficients, results of the linearity test ( $p$-values) and directional coefficients of the lines estimated assuming the model $y=a^{*} x$.

For all tasks $r_{p}$ is higher than 0.7. The strongest correlation between the results (In $t$ ) from the two series was found for the test "Board". The values of the Spearman's coefficients are also high. As follows from the linearity test, for the results of all tasks $p>0.05$, so the linear correlations are statistically significant.

Table 2 presents statistical analysis data for the corresponding results obtained for nondominant hand. The number of children is not specified as it is exactly equal to that in Table 1. As follows from the second column data, for all tests except the "Centres" the values of the coefficient $r_{p}$ are a bit lower than the corresponding ones obtained for the dominant hand (Table 1). Hence, it can be concluded that the results obtained with a weaker hand are more random. Moreover, the confidence interval of the linearity test for the results obtained for the test "Labyrinth" is smaller than the assumed level of significance, which indicates a deviation from linear correlation. 
Table 1. Values of Pearson's $\left(r_{p}\right)$ and Spearman's $\left(r_{s}\right)$ correlation coefficients for the results obtained when performing tests with the dominant hand, $p$-values obtained from the linearity test and the linear coefficient $a$. The first column gives the tasks, while the second (denoted by $n$ ) - the total number of children having performed the task

\begin{tabular}{l|c|cc|c|c}
\hline \multirow{2}{*}{ Tasks } & $n$ & Pearson's test & Spearman's test & $\begin{array}{c}\text { Linearity Test } \\
p \text {-value }\end{array}$ & Coefficient $a$ \\
\cline { 3 - 5 } & 39 & $r_{p}$ & $r_{s}$ & 0.7583 & 0.9586 \\
\hline Blocks & 37 & 0.8855 & 0.9454 & 0.5146 & 1.018 \\
Labyrinth & 35 & 0.738 & 0.7224 & 0.5959 & 0.8912 \\
Ball & 34 & 0.902 & 0.8692 & 0.1122 & 0.9783 \\
Circle & 36 & 0.9717 & 0.9688 & 0.9186 & 0.9851 \\
Board & 38 & 0.8745 & 0.8779 & 0.694 & 0.9996 \\
Centres & 61 & 0.9822 & 0.9773 & 0.8755 & 0.9822 \\
Hand grip strength & 61 & 0.7773 & 0.7761 & 0.6034 & 0.9697 \\
\hline Nine-Hole Peg Test & & & & &
\end{tabular}

Table 2. Values of Pearson's $\left(r_{p}\right)$ and Spearman's $\left(r_{s}\right)$ correlation coefficients for the results obtained when performing tests with the non-dominant hand, $p$-values obtained from the linearity test and the linear coefficient $a$

\begin{tabular}{l|cc|c|c}
\hline \multirow{2}{*}{ Tasks } & Pearson's test & Spearman's test & $\begin{array}{c}\text { Linearity Test } \\
p \text {-value }\end{array}$ & Coefficient $a$ \\
\cline { 2 - 3 } Blocks & $r_{p}$ & $r_{s}$ & 0.5419 & 0.9723 \\
Labyrinth & 0.8639 & 0.9132 & 0.0265 & 0.9817 \\
Ball & 0.7555 & 0.7166 & 0.2831 & 0.9069 \\
Circle & 0.6161 & 0.5911 & 0.6448 & 0.9768 \\
Board & 0.8281 & 0.8072 & 0.2049 & 0.9921 \\
Centres & 0.9329 & 0.9256 & 0.694 & 0.9996 \\
Hand grip strength & 0.8613 & 0.882 & 0.6034 & 0.9680 \\
Nine-Hole Peg Test & 0.9745 & 0.9720 & 0.0988 & 0.9737 \\
\hline
\end{tabular}

Similar task completion time analysis but in the real time domain is given in Appendix.

\section{ANALYSIS OF MEANS}

Statistical significance of the differences between the mean values calculated for the whole group of the children studied in the two series of measurements was determined, taking into account the logarithms of times of the task performance obtained for all the children. The results are given in Tables 3 and 4, both for the dominant and non-dominant hand in the case of our computer tests. The subsequent columns of Table 3 include: particular tests, mean values of logarithms of the test completion ( $\ln t$ ), standard deviations (SD) and standard errors of arithmetic mean (SEM) for the results obtained in the first and second series of measurements. The last two 
columns give the $p$-value obtained from the Kolmogorov-Smimov test and the $p$-value from the t-Student test.

Table 3. The mean values of the logarithms of the time completion (In $t$ ), standard deviations (SD) and standard error of means (SEM) for the dominant hand; $p$-values calculated from the Kolmogorov-Smirnov test and the $t$-Student test are given in the last two columns

\begin{tabular}{|c|c|c|c|c|c|c|c|c|}
\hline \multirow{2}{*}{ Tasks } & \multicolumn{3}{|c|}{1 measurement } & \multicolumn{3}{|c|}{2 measurement } & \multirow{2}{*}{$\begin{array}{l}p \text {-value of the } \\
\text { Kolmogorov- } \\
\text { Smirnov test }\end{array}$} & \multirow{2}{*}{$\begin{array}{c}\text { p-value } \\
\text { of the } \\
t \text {-Student test }\end{array}$} \\
\hline & $\ln t_{1}$ & $\mathrm{SD}$ & SEM & $\ln t_{2}$ & SD & SEM & & \\
\hline Blocks & 2.373 & 0.5195 & 0.08318 & 2.303 & 0.4132 & 0.06617 & $p>0.1$ & 0.0866 \\
\hline Labyrinth & 2.705 & 0.5429 & 0.08926 & 2.765 & 0.5832 & 0.09588 & $p>0.1$ & 0.2397 \\
\hline Ball & 0.6795 & 0.3531 & 0.05969 & 0.6231 & 0.3788 & 0.06402 & $p>0.1$ & 0.2175 \\
\hline Circle & 2.373 & 0.4958 & 0.08502 & 2.323 & 0.5289 & 0.09071 & $p>0.1$ & 0.2136 \\
\hline Board & 3.541 & 0.5612 & 0.09354 & 3.437 & 0.5113 & 0.08521 & $p>0.1$ & 0.0356 \\
\hline Centres & 3.193 & 0.2661 & 0.04317 & 3.233 & 0.2767 & 0.04488 & $p>0.1$ & 0.0766 \\
\hline
\end{tabular}

Table 4. The mean values of the logarithms of the time completion (ln $t$ ), standard deviations (SD) and standard error of means (SEM) for the non-dominant hand; $p$-values calculated from the KolmogorovSmirnov test and the $t$-Student test are given in the last two columns

\begin{tabular}{|c|c|c|c|c|c|c|c|c|}
\hline \multirow{2}{*}{ Tasks } & \multicolumn{3}{|c|}{1 measurement } & \multicolumn{3}{|c|}{2 measurement } & \multirow{2}{*}{\begin{tabular}{|c|}
$\begin{array}{c}\mathrm{p} \text {-value } \\
\text { of the } \\
\text { Kolmogorov- } \\
\text { Smirnov test }\end{array}$ \\
\end{tabular}} & \multirow{2}{*}{$\begin{array}{c}p \text {-value } \\
\text { of the } \\
t \text {-Student test }\end{array}$} \\
\hline & $\ln t_{1}$ & SD & SEM & $\ln t_{2}$ & SD & SEM & & \\
\hline Blocks & 2.652 & 0.3721 & 0.05958 & 2.586 & 0.3587 & 0.05744 & $p>0.1$ & 0.0363 \\
\hline Labyrinth & 3.029 & 0.5052 & 0.08306 & 2.999 & 0.4487 & 0.07376 & $p>0.1$ & 0.5923 \\
\hline Ball & 0.8432 & 0.4014 & 0.06785 & 0.7975 & 0.4757 & 0.08041 & $p>0.1$ & 0.4925 \\
\hline Circle & 2.574 & 0.3599 & 0.06173 & 2.513 & 0.4348 & 0.07457 & $p=0.0694$ & 0.1548 \\
\hline Board & 3.79 & 0.3831 & 0.06386 & 3.763 & 0.3682 & 0.06137 & $p>0.1$ & 0.2579 \\
\hline Centres & 3.41 & 0.2428 & 0.03937 & 3.411 & 0.2391 & 0.03879 & $p>0.1$ & 0.9528 \\
\hline
\end{tabular}

Since in the Kolmogorov-Smirnov test $p>0.1$, also in the case of our measurements transformation of the results of each test ensured a normal distribution. Having it ensured, the statistical significance of the differences between the mean logarithms was checked by the $t$-Student test. The statistically significant differences were obtained only for the results of the test "Board".

The corresponding results obtained for the non-dominant hand are presented in Table 4. Also for the weaker hand the results of all the tests have a normal distribution $(p>0.07)$. Results of the $t$-Student test have shown statistically significant differences $(p<0.04)$ between the mean times of completion of test "Blocks". 


\section{DISCUSSION}

Literature provides descriptions of many tests of manual dexterity and some of them have been widely applied in clinical practice. The most commonly used are: the test of the functional state of the hand proposed by Jebsen-Taylor [5, 20], manual functioning test proposed by Smith [17], Frenchay Activity Scale [14, 21], manual dexterity Box and Block Test [3, 9], Nine-Hole Peg Test and Fifty-Hole Peg Test [7] and their contemporary version Purdue Pegbord Test [18], tests of dexterity of fingers and wrist [15], Rosenbusch test [18] of fingers dexterity and functional tests [4] being some modifications of the above-mentioned tests. Other important methods are the Sequential Occupational Dexterity Assessment (SODA) [19] and a method based on accelerometric measurements [16]. However, there is surprisingly few tests based on the assessment of motor functions of the hand when performing computer-based tasks. The use of computer has been limited to that of a tool helping dynamometric examinations [7], whereas reports on a direct use of computers in diagnostics of upper extremity have appeared only recently. In one of recent reports the dexterity of the elbow joint after hemiparesis [12] was assessed by testing the ability of the hand to follow an object moving on a computer screen, when the movements of the hand were restricted to those in the elbow joint.

None of the so far proposed methods for assessment of hand dexterity exhausts all aspects of the hand motions, there is no agreement as to the adequacy of the methods or their applicability to all groups of patients. The diversity of clinical problems requires a diversity of tests checking dexterity of the hand [11]. In our previous work [6] we proposed computer tests of dexterity of both hands. The application was performed in Visual Basic working in the Windows platforms. The norms of natural logarithms of times (in seconds) have been established for performance of particular tasks by school children in three age groups. Statistical significance of the differences of the means of the logarithms of times of task completion was also proven for all the tests and chosen groups of children.

In order to verify the tests proposed in [6] a study was performed in a group of 84 healthy children asked to perform 6 tests tasks and repeat the performance after a week. The results were analysed in the aspect of their repeatability. The correlation coefficients measuring the reliability of the tests were calculated. The values of the Pearson's coefficients are close to those determined for dynamometric tests [10] $(0.83<r<0.88$, depending on the kind of grip) and functional tests. For example in [5] $0.60<r<0.99$, depending on the hand and test chosen; in [18] $0.68<r<0.88$; in [3] $0.89<r<0.97$, and in [19] $r=0.93$. The results confirm clinical usefulness of our computer tests and indicate that the repeatability of results for the non-dominant hand is poorer than that for the dominant hand. Similar observations can be found for the tests given in literature [5].

Finally, as the test-retest reliability study for the dynamometric tests have been performed for adults, we have run two series of measurements in a separate group of 61 children. The corresponding correlation coefficients (including those for Nine-Hole Peg Test) are collected in the last two rows in Table 1 and Table 2 for the dominant and non-dominant hand, respectively. We emphasise that the Pearson's coefficients for the hand grip measurements found 
here in the group of children are higher than those known from the study among adults [10]. From the other hand, the Nine-Hole-Peg Test widely used for the assessment of the manual dexterity displays somewhat lower value of the Pearson's coefficients with respect to those found for the computer tests, especially for the dominant hand.

\section{CONCLUSIONS}

1. The computer tests checking the manual dexterity proposed in [6] have been proved to be testretest reliable.

2. The hand grip strength measurements, using the JAMAR dynamometer, show the highest testretest reliability. As to the Nine-Hole Peg Test, its reliability for the dominant hand is lower than that for our computer tests.

3. The results of the computer tests have not revealed a bias ascribed to the learning effect.

4. A proper computer program can be used for determination of assessment of the hand dexterity.

\footnotetext{
APPENDIX

A separate analysis has been performed for the obtained real times (in seconds) of completion of all the six computer tasks. Results of the relevant correlation and regression analyses are collected in Tables A1 and A2.

As follows from the Table A1 data, for all tasks performance a strong positive correlation was obtained, a bit weaker than for the transformed variables (Table 2). The Pearson's coefficient takes values from the range $0.70 \leq r_{p} \leq 0.95$, and the strongest con-elation was noted for the task "The board". High values of the Spearman's coefficients testify to a strong correlation. It should be emphasised that for the data from all tasks performance the $p$-value of the linearity test is higher than the level of significance of $\alpha=0.05$, so there are no statistically significant deviations of the distribution from linearity.

Table A2 gives the values of the Pearson's and Spearman's coefficients, the level of confidence of the linearity test and the direction coefficient obtained for the dependence of the real task completion time for the non-dominant hand. The weakest correlation between the times of the two measurements has been noted for the task "The ball".

Tables A3 and A4 present results of the analysis of differences between the mean values obtained in two series of measurements performed by the dominant and non-dominant hand. The first column of Table A3 specifies the tasks, the next columns give the mean times of task completion $(t)$, standard deviations (SD) and standard errors of the arithmetic mean (SEM) obtained in the first measurement. The subsequent three columns present the corresponding values obtained in the second measurement. The eighth column gives the $p$-values of the Kolmogorov-Smirnov test checking the normality of the distribution. The last column gives the $p$-values of the parametric $t$-Student test or non-parametric Wilcoxon test applied when the data did not have a normal distribution.
} 
According to the results of Kolmogorov-Smirnov analysis, the data collected from the two tasks ("The blocks" and "The board") do not have normal distribution. Moreover, for the two tasks, the results of the Wilcoxon test have shown that the mean times of the tasks performance show statistically significant differences.

Table A1. The Pearson's $\left(r_{p}\right)$ and Spearman's $\left(r_{s}\right)$ correlation coefficients for the tasks performed by the dominant hand in the real time, $p$-values of the linearity test and the corresponding direction cosine values

\begin{tabular}{l|cc|c|c}
\hline \multirow{2}{*}{ Tasks } & Pearson's test & Spearman's test & $\begin{array}{c}\text { Linearity Test } \\
p \text {-value }\end{array}$ & Coefficient $a$ \\
\cline { 2 - 3 } & $r_{p}$ & $r_{s}$ & 1.000 & 0.8272 \\
Blocks & 0.7726 & 0.9454 & 0.5146 & 1.055 \\
Labyrinth & 0.7574 & 0.8778 & 0.3741 & 0.9207 \\
Ball & 0.6997 & 0.7235 & 0.3091 & 0.9686 \\
Circle & 0.8993 & 0.8692 & 0.9186 & 0.9258 \\
Board & 0.9474 & 0.9688 & 0.6133 & 1.035 \\
Centres & 0.8642 & 0.8779 & \\
\hline
\end{tabular}

Table A2. The Pearson's $\left(r_{p}\right)$ and Spearman's $\left(r_{s}\right)$ correlation coefficients for the tasks performed with the non-dominant hand in the real time, $p$-values of the linearity test and the corresponding direction cosine values

\begin{tabular}{l|cc|c|c}
\hline \multirow{2}{*}{ Tasks } & Pearson's test & Spearman's test & $\begin{array}{c}\text { Linearity Test } \\
p \text {-value }\end{array}$ & Coefficient $a$ \\
\cline { 2 - 3 } & $r_{p}$ & $r_{s}$ & 0.6347 & 0.9010 \\
Blocks & 0.772 & 0.9132 & 0.3227 & 0.8697 \\
Labyrinth & 0.6769 & 0.7166 & 0.2831 & 0.9414 \\
Ball & 0.6349 & 0.5911 & 0.5636 & 0.9643 \\
Circle & 0.7781 & 0.8072 & 0.5511 & 0.9521 \\
Board & 0.9265 & 0.9256 & 0.694 & 0.9928 \\
Centres & 0.883 & 0.882 & \\
\hline
\end{tabular}

Table A3. The mean values of the time of the tasks completion $(\bar{t})$, standard deviations (SD) and standard errors of the arithmetic mean (SEM) for the dominant hand and $p$-values obtained from the Kolmogorov-Smirnov test for the normalcy of distribution, from the $t$-Student and Wilcoxon tests

checking the significance of the differences between the mean values of the tasks completion times

\begin{tabular}{|c|c|c|c|c|c|c|c|c|}
\hline \multirow{2}{*}{ Tasks } & \multicolumn{3}{|c|}{1 measurement } & \multicolumn{3}{|c|}{2 measurement } & \multirow{2}{*}{$\begin{array}{c}p \text {-value of } \\
\text { the Kolmogorov } \\
\text { Sinirnov test }\end{array}$} & \multirow{2}{*}{$\begin{array}{c}p \text {-value of } \\
\text { the Wilcoxon or } \\
t \text {-Student test }\end{array}$} \\
\hline & $t_{1}$ & SD & SEM & $t_{2}$ & $\mathrm{SD}$ & SEM & & \\
\hline Blocks & 12.24 & 6.608 & 1.058 & 10.92 & 5.117 & 0.8194 & 0.002 & 0.0243 \\
\hline Labyrinth & 17.114 & 8.853 & 1.455 & 18.647 & 10.777 & 1.772 & $p>0.1$ & 0.1953 \\
\hline Ball & 2.108 & 0.8753 & 0.148 & 2.012 & 0.8986 & 0.1519 & $p=0.0669$ & 0.4158 \\
\hline Circle & 12.12 & 6.41 & 1.099 & 11.759 & 6.862 & 1.177 & $p>0.1$ & 0.4896 \\
\hline Board & 40.346 & 23.919 & 3.987 & 38.038 & 22.118 & 3.686 & 0.0421 & 0.032 \\
\hline Centres & 25.236 & 7.107 & 1.153 & 26.331 & 7.563 & 1.227 & $p>0.1$ & 0.0876 \\
\hline
\end{tabular}


Table A4. The mean values of the tasks completion times $(\bar{t})$, standard deviations (SD) standard errors of the arithmetic mean (SEM) for the non-dominant hand, $p$-values obtained from the Kolmogorov-Smirnov test for the normalcy of distributions, from $t$-Student or Wilcoxon tests for the significance of differences between the mean values of the task completion times

\begin{tabular}{|c|c|c|c|c|c|c|c|c|}
\hline \multirow{2}{*}{ Tasks } & \multicolumn{3}{|c|}{1 measurement } & \multicolumn{3}{|c|}{2 measurement } & \multirow{2}{*}{$\begin{array}{c}p \text {-value } \\
\text { of the } \\
\text { Kolmogorov- } \\
\text { Smirnov test }\end{array}$} & \multirow{2}{*}{$\begin{array}{c}p \text {-value } \\
\text { of the } \\
\text { Wilcoxon or } \\
\text { t-Student test }\end{array}$} \\
\hline & $t_{1}$ & SD & SEM & $t_{2}$ & SD & SEM & & \\
\hline Blocks & 15.176 & 5.789 & 0.927 & 14.135 & 5.15 & 0.8246 & 0.0159 & 0.0275 \\
\hline Labyrinth & 23.254 & 11.334 & 1.863 & 21.994 & 9.05 & 1.488 & $p>0.1$ & 0.3706 \\
\hline Ball & 2.521 & 1.106 & 0.187 & 2.48 & 1.245 & 0.2105 & $p>0.1$ & 0.8124 \\
\hline Circle & 13.905 & 4.529 & 0.7768 & 13.45 & 5.445 & 0.9337 & 0.0444 & 0.1239 \\
\hline Board & 47.669 & 19.877 & 3.313 & 46.157 & 18.373 & 3.062 & $p>0.1$ & 0.2331 \\
\hline Centres & 31.13 & 7.564 & 1.227 & 31.14 & 7.379 & 1.197 & $p>0.1$ & 0.9856 \\
\hline
\end{tabular}

Table A4 presents results of analysis of the mean times of the tasks completion for the nondominant hand. The structure of Table A4 is the same as that of Table A3. As follows from the results for non-dominant hand, the data for "The blocks" and "The circle" did not show normal distribution. Results of the non-parametric Wilcoxon test have proved statistically significant differences between the mean times of completion of the task "The blocks" in the first and second measurements.

\section{Acknowledgements}

The partial support from the PFRON Foundation via the grant No. 695/30/WZDS/FRI/00 is acknowledged.

\section{References}

[1] J. Bear-Lehman, B. C. Abreu, Phys. Ther., 69, 1025 (1989).

[2] L. Denisiuk, Badania nad wartościa niektórych prób sprawnościfizycznej. Wychowanie Fizyczne i Sport, 3, 327(1961).

[3] J. Desrosiers, G. Bravo, R. Hebert, E. Dutil, L. Mercier, Arch. Phys. Med. Rehabil., 75, 751 (1994).

[4] J. Dylewicz, A. Mołczakow, G. Radecka, Materiały Sesji Naukowej PAN, pp. 84-90, Poznań 1983

[5] R. H. Jebsen, N. Taylor, R. B. Trieschman, M. J. Trotter, L. A. Howard, Arch. Phys. Med. Rehabil., 50,311 (1969).

[6] M. Kamieniarz, W. Stryła, P. Haglauer, G. Kamieniarz, Comp. Meth. Scie. Tech., 5, 25 (1999). M. Kamieniarz, W. Stryła, P. Haglauer, G. Kamieniarz, Post. Rehabil., XV, 25 (2001).

[7] M. Kellor, J. Frost, N. Silberberg, I. Iversen, R. Cummings, Am. J. Occup. Ther., 25, 77 (1971).

[8] D. Magnusson, Wrowadzenie do teorii testów, PWN, Warszawa 1981.

[9] V. Mathiowetz, G. Volland, N. Kashman, K. Weber, Am. J. Occup. Ther., 39, 386 (1985).

[10] V. Mathiowetz, K. Weber, G. Volland, N. Kashman, J. Hand Surg., 9A, 222 (1984)

[11] S. D. McPhee, Am. J. Occup. Ther., 41, 158 (1987).

[12] N. J. O'Dwyer, L. Ada, P. D. Neilson, Brain, 119, 1737 (1996).

[13] W. Osiński, Pomiar w badaniach nad motorycznościa człowieka, Motoryczność Człowieka - Jej struktura, Zmienność i Uwarunkowania, pp. 189-206, Poznań 1993. 
[14] V. M. Parker, D. T. Wade, R. L Hewer, Int. Rehabil. Med., 8, 69 (1986).

[15] Cz. Piskorz, E. Klimek-Piskorz, Post. Rehabil., IX, 31 (1995).

[16] D. Reddihough, T. Bach, G. Burgess, L. Oke, I. Hudson, Develop. Med. Child Neurol., 33, 578. (1991).

[17] H. B. Smith, Am. J. Occup. Ther., 27, 244 (1973).

[18] C. Stein, E. J. Yerxa, Am. J. Occup. Ther., 44, 499 (1990).

[19] S. van Langveld, P. van Pad Bosch, J. Bakker, S. Terwindt, M. Fraussen, P. van Riel, J. Hand Ther., 9,27(1996).

[20] T. P. Vliet Vlieland, T. P. van der Wijk, I. M. Jolie, A. H. Zwinderman, J. M. Hazes, J. Reumatol., 23, 835 (1996).

[21] D. T. Wade, R. Langton- Hewer, V. A. Wood, C. E. Skilbeck, H. M. Ismail, J. Neurol. Neurosurg. Psychiatry, 46, 521 (1983). 